\title{
Modeling complex genetic and environmental influences on comorbid bipolar disorder with tobacco use disorder
}

\author{
Richard C McEachin ${ }^{1,2^{*}}$, Nancy L Saccone ${ }^{3}$, Scott F Saccone ${ }^{4}$, Yelena D Kleyman-Smith ${ }^{5}$, Tiara Kar ${ }^{5}$, Rajesh K Kare ${ }^{5}$,
} Alex S Ade ${ }^{2}$, Maureen A Sartor ${ }^{2}$, James D Cavalcoli², Melvin G Mclnnis ${ }^{1,2}$

\begin{abstract}
Background: Comorbidity of psychiatric and substance use disorders represents a significant complication in the clinical course of both disorders. Bipolar Disorder (BD) is a psychiatric disorder characterized by severe mood swings, ranging from mania to depression, and up to a 70\% rate of comorbid Tobacco Use Disorder (TUD). We found epidemiological evidence consistent with a common underlying etiology for BD and TUD, as well as evidence of both genetic and environmental influences on BD and TUD. Therefore, we hypothesized a common underlying genetic etiology, interacting with nicotine exposure, influencing susceptibility to both BD and TUD.

Methods: Using meta-analysis, we compared TUD rates for BD patients and the general population. We identified candidate genes showing statistically significant, replicated, evidence of association with both BD and TUD. We assessed commonality among these candidate genes and hypothesized broader, multi-gene network influences on the comorbidity. Using Fisher Exact tests we tested our hypothesized genetic networks for association with the comorbidity, then compared the inferences drawn with those derived from the commonality assessment. Finally, we prioritized candidate SNPs for validation.
\end{abstract}

Results: We estimate risk for TUD among BD patients at 2.4 times that of the general population. We found three candidate genes associated with both BD and TUD (COMT, SLC6A3, and SLC6A4) and commonality analysis suggests that these genes interact in predisposing psychiatric and substance use disorders. We identified a 69 gene network that influences neurotransmitter signaling and shows significant over-representation of genes associated with BD and TUD, as well as genes differentially expressed with exposure to tobacco smoke. Twenty four of these genes are known drug targets.

Conclusions: This work highlights novel bioinformatics resources and demonstrates the effectiveness of using an integrated bioinformatics approach to improve our understanding of complex disease etiology. We illustrate the development and testing of hypotheses for a comorbidity predisposed by both genetic and environmental influences. Consistent with our hypothesis, the selected network models multiple interacting genetic influences on comorbid BD with TUD, as well as the environmental influence of nicotine. This network nominates candidate genes for validation and drug testing, and we offer a panel of SNPs prioritized for follow-up.

\section{Background}

Bipolar Disorder (BD) is a severe psychiatric disorder, characterized by periods of mania and depression, which affects approximately $1 \%$ of the U.S. population, or 3 $5 \%$ if $\mathrm{BD}$ spectrum disorders (BPII and BP-NOS) are included [1,2]. Tobacco Use Disorder (TUD) is the

\footnotetext{
* Correspondence: mceachin@umich.edu

'Department of Psychiatry, University of Michigan, Ann Arbor, MI, USA
}

single greatest cause of preventable death in the United States $[3,4]$ and it disproportionately affects psychiatric patients [5]. Note that TUD is defined as "Tobacco used to the detriment of a person's health or social functioning. Tobacco dependence is included.", according to the Medical Subject Heading (MeSH) index [6]. In earlier work, various research groups used "nicotine dependence", "nicotine addiction", "tobacco dependence", or 
"smoking" to characterize the phenotype, but there is no clear standard term in the literature. We use the MeSH term, TUD, in these analyses because it incorporates the information derived from these multiple sources and facilitates the bioinformatics analyses. There is evidence of increased risk for TUD among BD patients [1,7-12] as well as evidence that smokers may be at increased risk for BD [1,9]. While it is possible that TUD could predispose individuals to $\mathrm{BD}$, or $\mathrm{BD}$ could predispose individuals to TUD, the observed bi-directional increased risk for both disorders is consistent with some common underlying etiology for BD and TUD.

There is epidemiological evidence of multiple genetic influences on both BD [13] and TUD [14]. In family and twin studies, heritability of BD is estimated at 75 to $85 \%$ $[15,16]$, consistent with one or more genetic influences on BD susceptibility. Still, even for monozygotic twins, concordance is estimated at only about $67 \%$ [17], consistent with environmental influences on BD susceptibility. Heritability of TUD is estimated at 37 to $56 \%$ for initiation of smoking, and 59 to $70 \%$ for transition to nicotine dependence $[18,19]$, consistent with one or more genetic influences on TUD susceptibility. In addition, nicotine binds to cell surface nicotinic acetylcholine receptors, and so represents an environmental effect which would be expected to influence intracellular signal transduction pathways. Given the potential for some common underlying etiology for BD and TUD, as well as evidence of genetic and environmental influences on both $\mathrm{BD}$ and TUD, we hypothesized a common underlying genetic etiology, interacting with environmental nicotine exposure, influencing susceptibility for both BD and TUD.

Figure 1 outlines the overall analysis flow. After assessing the strength of evidence for comorbidity of BD and TUD via meta-analysis, and seeing an increased Relative Risk consistent with some common etiology, we identified candidate genes for the comorbidity. The analysis then followed two parallel paths. First, in complex diseases multiple genetic influences converge on a single phenotype (in this case, co-morbid BD with TUD). We presume that to influence a single phenotype these multiple genetic influences must impact some common element(s) associated with the phenotype (e.g., a common pathway, tissue, cellular function, disease or other process). We exploited this convergence on a single phenotype by identifying significant commonality among the selected candidate genes. We then used this commonality to improve our understanding of the roles of these genes in both BD and TUD. In a parallel analysis, we generated networks of genes that interact with our selected candidate genes. Based on these interactions, we hypothesized models of the larger set of genetic influences on co-morbid BD with TUD, then tested each of these hypotheses for enrichment of BD and
TUD associated genes. As with the commonality analysis, analysis of gene networks enriched for BD and TUD associated genes may improve our understanding of the comorbidity, so we compared lessons learned in the commonality and network analyses. Finally, while no GWA studies have yet been conducted specifically to identify candidate genes for this co-morbidity, we prioritized Single Nucleotide Polymorphisms (SNPs) for follow-on studies by functional data, as well as by combining evidence from two GWA studies (one for BD and one for TUD).

\section{Methods}

\section{Meta-analysis (Figure 1a)}

We first assessed the strength of evidence for comorbidity of BD and TUD, based on the published literature. Querying all of PubMed, we found seven studies published on the subject between 1986 and 2008 [1,7-12]. From each study, we selected the data specific to comorbid BD with TUD and ensured that the phenotypes studied were consistent, then generated a combined spreadsheet of the raw data (Additional file 1, Forest Notes). Using MIX Meta-Analysis software $[20,21]$ (version 1.7), we generated an annotated forest plot of Relative Risk, using first a fixed effects model

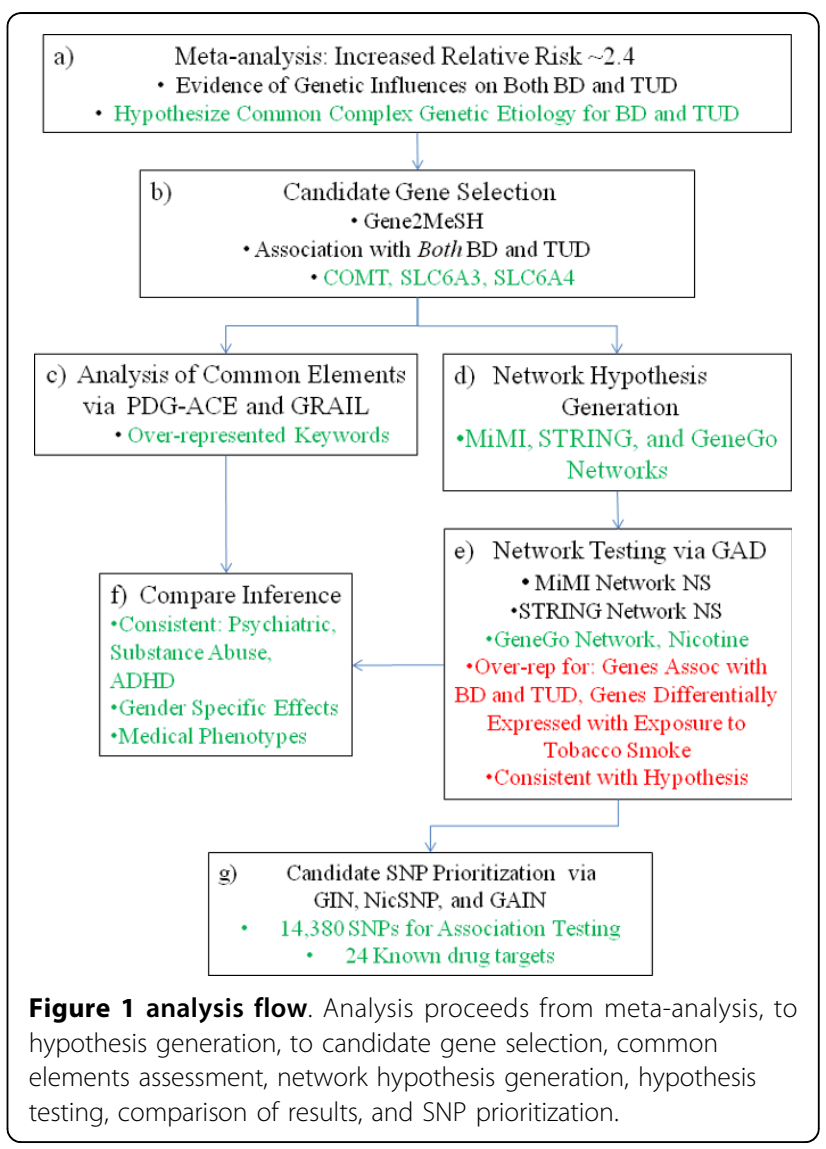


with Mantel-Haenszel weighting then a random effects model with DerSimonian-Laird weighting. All other MIX parameters were set at the default values, under the Analysis/preferences tab. For details of the metaanalysis see Additional file 2, MOOSE Checklist [22].

\section{Candidate gene selection (Figure $\mathbf{1 b}$ )}

We used Gene2MeSH [23], a novel bioinformatics resource from the National Center for Integrative Biomedical Informatics (NCIBI), to select candidate genes for comorbid BD with TUD on 8 April, 2009. Gene2$\mathrm{MeSH}$ identifies genes and $\mathrm{MeSH}$ terms that co-occur in PubMed-indexed manuscripts that are annotated for both the genes referenced and the MeSH terms assigned. Gene2MeSH allows the user to input a MeSH term and find all genes significantly over-represented in publications annotated for that term. In this mode, Gene2MeSH requires $\mathrm{MeSH}$ terms as input and we used the $\mathrm{MeSH}$ database [6] to identify appropriate $\mathrm{MeSH}$ terms to query Gene2MeSH for genes related to BD and TUD. $\mathrm{MeSH}$ has only one term for BD, "bipolar disorder", which we used in the Gene2MeSH query to identify a preliminary set of human BD candidate genes. In addition to TUD, MeSH has two related terms so we queried "tobacco use disorder", "nicotine" and "smoking", then used the union of these three human gene sets as a preliminary set of TUD candidate genes.

Gene2Mesh generates a Fisher Exact p-value to quantify the over-representation of genes occurring in publications annotated for a given $\mathrm{MeSH}$ term, relative to all papers in PubMed, and select genes based on a threshold of Fisher Exact p-value $\leq 10^{-4}$. However, co-occurrence of genes with $\mathrm{MeSH}$ terms is not the same as association. We tested each preliminary candidate gene for evidence of association between the gene and the appropriate phenotype (i.e., BD or TUD) by reading the papers cited by Gene2MeSH. We accepted in our final "overlapping" set only those preliminary candidate genes for which we found at least two studies that showed statistically significant positive association (Bonferroni corrected p-value $\leq 0.05$ ) with both $B D$ and TUD, in the peer reviewed literature. We did not consider power, as this parameter is generally not reported in the literature.

\section{Common elements (Figure 1c)}

In complex diseases, multiple genetic influences converge on a single phenotype, consistent with some common element(s) among these genetic influences (e.g., a common disease process, metabolic or signaling pathway, cellular component, or tissue expression). Understanding commonality among our candidate genes may yield useful inference on how multiple genetic influences converge on the co-morbidity. We assessed two resources available for commonality testing: PDG-ACE (Prioritizing Disease Genes by Analysis of Common Elements) [24,25] from NCIBI, and GRAIL (Gene
Relationships Across Implicated Loci) [26] from the Broad Institute. Both PDG-ACE and GRAIL generate hypotheses on gene-gene interactions and also provide quantitative measures of the strength of evidence in support of each hypothesis.

PDG-ACE identifies significant commonality across genetic loci based on text in the Entrez Gene records of genes at locus pairs. We submitted our set of three overlapping candidates to PDG-ACE in pairs, performed $10^{7}$ iterations for significance testing using PDG-ACE's $\mathrm{MeSH}$-derived controlled vocabulary of 2,531 keywords, applied a Bonferroni correction for these 2,531 hypothesis tests, and stored the keywords that were significantly over-represented (corrected p-value $\leq 0.05$ ) at each locus pair. For these stored keywords, we assessed the context of each keyword in the Entrez Gene records for each locus and retained those keywords that were used in the same context at both loci. Since the Entrez Gene records for these genes include links to the PubMed abstracts, we followed each of these links to identify trends that may be useful in understanding the roles of these genes in co-morbid BD with TUD.

GRAIL also finds commonality among genes, though, with GRAIL commonality is based on PubMed abstracts. On 8 July, 2009, we input our overlapping candidates to the GRAIL server and set the query regions to equal the seed regions, as recommended in the GRAIL FAQs when the number of input genes is small. We compared the returned keywords associating the overlapping candidate genes to our PDG-ACE results and assessed their context with respect to comorbid BD with TUD.

\section{Hypothesis generation: network model building (Figure} 1d)

We assessed three resources for building models of genetic interactions among our candidate genes: MiMI (Michigan Molecular Interactions) from NCIBI [27], STRING (Search Tool for the Retrieval of Interacting Genes/Proteins) from the European Molecular Biology Lab [28,29], and MetaCore [30] from GeneGo Inc. Each of the models developed using these resources represents one hypothesis on how multiple genetic variants could interact to influence the comorbidity. To focus on the interactions most closely tied to the overlapping candidate genes (and, we assume, most likely to influence comorbid BD with TUD), we set input parameters to accept only the highest quality interactions data and to build the smallest network that includes all of the overlapping candidate genes in a single model.

MiMI includes comprehensive protein interaction information that has been integrated and merged from diverse protein interaction databases. For input of multiple genes, MiMI is implemented as a plug-in for Cytoscape [31] (version 2.6.0), an open source bioinformatics platform for visualizing molecular interaction networks. 
MiMI does not have a parameter for selecting the level of confidence for interactions. We input our list of three overlapping candidate genes and selected the "Interactions among query genes" option. This network did not include all three of the overlapping candidates in a single network so we moved to the "Query Genes + Nearest Neighbors" option and this produced a single network including all three overlapping candidates. We downloaded the network in both graphical and text formats.

STRING is a database of known and predicted protein interactions including: direct (physical) and indirect (functional) associations derived from genomic context, high-throughput experiments, conserved co-expression, and publications. We input our list of overlapping candidate genes, set the minimum combined score to 0.900 (highest confidence) and built the network. The resulting network did not connect the three overlapping candidate genes, so we had STRING add nodes to the network, one at a time, until all of the overlapping candidate genes were included in a single network. We downloaded the network in both graphical and text formats.

MetaCore (GeneGo Inc.) is a commercial database of human curated data on gene-gene, gene-DNA, and gene-small molecule interactions. The types of interactions data available are equivalent to those available in STRING. Starting with our three overlapping candidates, we set parameters for the "Shortest Paths" network building algorithm and "curated only" data, accepting unspecified effects as well as functional and binding interactions (MetaCore version 6.0). We first looked for direct interactions, then increased the number of nodes allowed between the overlapping candidate genes until they were all included in a single network. The resulting network is comparable to the MiMI and STRING networks.

An important feature of GeneGo, not yet available in MiMI or STRING, is that it allows the user to add selected nodes (genes, small molecules, etc.) to an established network. To help assess the environmental impact of nicotine on the hypothesized network for comorbid BD with TUD, we added nicotine to the network. GeneGo has a built in test for over-representation of genes in documented pathways, so we tested the network for pathway association. We downloaded both GeneGo networks, one excluding nicotine and one including nicotine, in both graphical and text formats.

\section{Hypothesis testing (Figure 1e)}

For each of our hypothesized networks, we first used the Genetic Association Database (GAD) [32] via the DAVID interface (Database for Annotation, Visualization and Integrated Discovery) [33,34], to test for overrepresentation of genes associated with BD and TUD. In addition, since nicotine represents an environmental influence on our hypothesized networks and differential gene expression is one of the most important ways that cells respond to the environment, we used NCIBI's ConceptGen [35] software application to test for differential gene expression related to $\mathrm{BD}$ and/or TUD.

GAD is an archive of results from human genetic association studies of complex diseases and disorders, which has been made available for assessment of gene sets via DAVID. If, based on GAD data, a given network is overrepresented for genes associated with both BD and TUD, the network may lead us to a clearer understanding of how the multiple genetic influences converge on the comorbidity. GAD provides dichotomous annotation of genes, based on published evidence, where each gene either has shown evidence or has not (yet) shown evidence of association with a specific phenotype (e.g. BD or TUD). DAVID uses this dichotomous annotation in a modified Fisher Exact test, where the count of positive agreement is reduced by 1 to make a more conservative test, to assess gene sets for over-representation of genes annotated for specific phenotypes. For each of the gene sets nominated by our network building tools (MiMI, STRING, and two GeneGo networks), we set DAVID to assess GENETIC_ASSOCIATION_DB_DISEASE functional annotation. The resulting tables provide test data including the False Discovery Rates (FDR) for specific disease phenotypes. We set FDR $\leq 5 \%$ as the threshold for over-representation of genes for any GAD phenotype. Each network, as a whole, may be over-represented for genes associated with BD and/or TUD. However, each of these networks includes the three overlapping candidates, which are already documented to be associated with both BD and TUD. As such, we tested each network a second time, excluding the overlapping candidates. The first test for each network serves as a positive control, where we expect to find evidence in GAD supporting association with BD and TUD. The second test, excluding the overlapping candidates, tests whether the network provides significant new information on association with BD and/or TUD, beyond the influence of the overlapping candidates.

In a second phase of hypothesis testing, we used ConceptGen [35] to test the genes in the larger GeneGo network for over-representation of genes differentially expressed with nicotine exposure. ConceptGen uses a custom-built analysis pipeline for processing Affymetrix GEO [36] datasets from raw data, testing for differentially expressed genes [37], then building concepts to represent the expression profiles. ConceptGen assesses over-representation of gene groups for given concepts by enrichment testing, using the same modified Fisher Exact test as in DAVID. After seeing significant overrepresentation of genes associated with BD and TUD in the GeneGo network that includes nicotine, we queried 
ConceptGen for "Gene Expression" concepts that show over-representation of the genes in this network. As in our GAD analysis, we set a threshold of FDR $\leq 0.05$ for over-representation of any differentially expressed gene set. (Note that ConceptGen presents FDR as a decimal value while GAD presents FDR as a percentage.) Inference from common elements versus network model building (Figure 1f)

The common elements analysis is based on only the overlapping candidate genes, while the network model building analysis includes additional candidate genes. Since these results are related, we compared the inference that could be drawn from the two approaches.

Prioritizing candidate SNPs for follow-on testing via GIN (Figure 1g)

We first prioritized SNPs in and near the genes in our selected network via the Genomic Information Network (GIN) method developed by Saccone et al. [38]. GIN prioritizes SNPs based on biological relevance, as determined by SNP/gene functional properties including synonymy, annotation for promoter regions, and human/mouse evolutionary conservation. Second, while there are not yet any published GWAS results for comorbid BD with TUD, we further prioritized SNPs by weighting them based on evidence from the NicSNP GWA $[39,40]$ study of nicotine dependence and the GAIN GWA study of BD[41].

\section{Results}

\section{Meta-analysis}

Based on our fixed effects model, we estimated Relative Risk for TUD among BD patients at 2.77, with a p-value $<0.01$, and a 95\% confidence interval of 2.62 to 2.92. Based on the random effects model, we estimated Relative Risk for TUD among BD patients at 2.39 , with a p-value $<0.0001$, and $95 \%$ confidence interval of 1.88 to 3.03 (Figure 2). In the random effects model, $\mathrm{Tau}^{2}$, an estimate of between-study variance, is small and the Q-index, a measure of lack of credibility among the studies, is zero (Additional file 3, Table S1). Since the Relative Risk estimates are consistent across the two models, we proceed with the more conservative estimate of 2.39 .

\section{Overlapping candidate genes}

Gene2MeSH-nominated candidates for comorbid BD with TUD include: catechol-O-methyltransferase (COMT, Entrez GeneID 1312); solute carrier family 6 (neurotransmitter transporter, dopamine), member 3 (SLC6A3, GeneID 6531); solute carrier family 6 (neurotransmitter transporter, serotonin), member 4 (SLC6A4, GeneID 6532); tryptophan hydroxylase 1 (TPH1, GeneID 7166); and dopamine receptor D4 (DRD4, GeneID 1815). Validating these preliminary candidate genes by searching for at least two studies showing statistically significant positive association (Bonferroni corrected p-value $\leq 0.05$ ) with both BD and TUD, we found that only COMT [42-47], SLC6A3 [48-57], and SLC6A4 [58-63] meet the requirement. TPH1 had one documented significant association with BD and one significant association with TUD, while DRD4 had four significant associations with TUD but only one significant association with BD.

\section{Common elements}

For all three locus pairs formed by our overlapping candidate genes, PDG-ACE reports "monoamine,

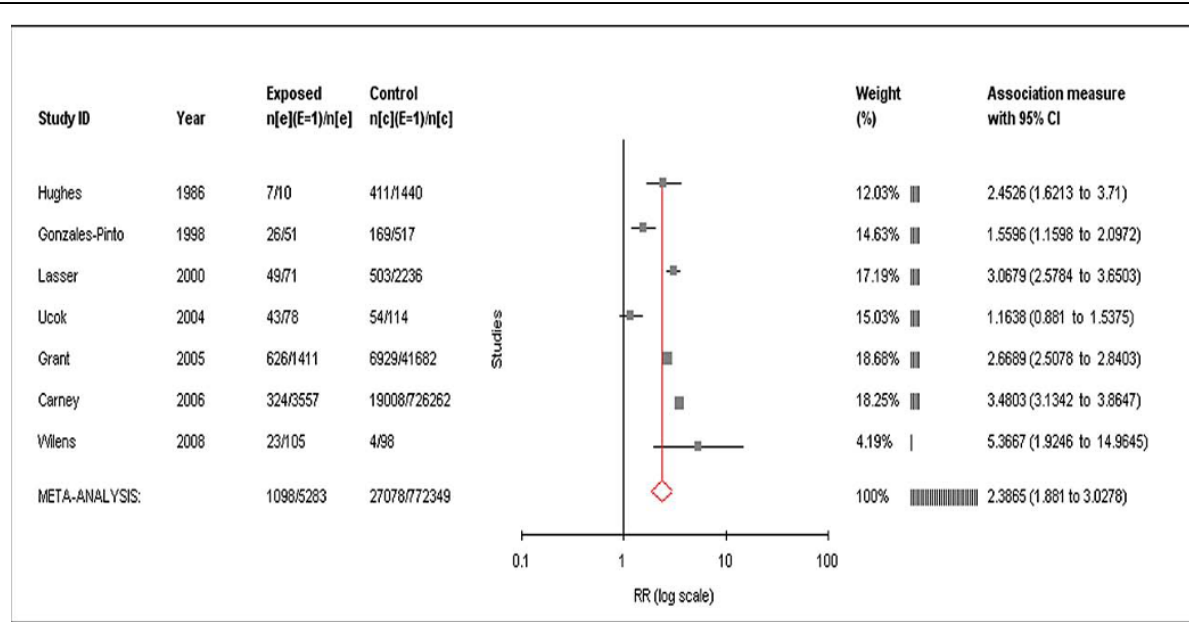

Figure 2 Annotated forrest plot of relative risk for TUD among BD patients. Study authors, dates, counts of smokers with BD, and counts of smokers among controls are shown on the left. On the right, the MIX software weights each study then calculates Relative Risk and 95\% confidence intervals for TUD among BD patients. A graphical representation of this data is seen in the middle. The META-ANALYSIS study summarizes the weighted contributions of each individual study and shows a Relative Risk of 2.39 for TUD among BD patients, with a 95\% confidence interval of 1.88 to 3.02 . 
psychiatric, and attention" as significantly over-represented keywords (Figure 3). For the COMT/SLC6A4 pair, "lithium, suicide, prefrontal cortex, illness, trait, and behavioral" were significantly over-represented. For the COMT/SLC6A3 pair, "norepinephrine and focused" were significantly over-represented. For SLC6A3/ SLC6A4, "methamphetamine and cocaine" were significantly over-represented. In assessing the context of these keywords in the Entrez Gene records of each locus, we noted that the keywords are consistent with psychiatric disorders, substance use disorders, and attention deficit hyperactivity disorder. In addition, the publications describing these effects indicate that these genes show gender specific effects with respect to both psychiatric disorders and substance use disorders [57,64-78]

GRAIL reported: "transporter, dopamine, serotonin, polymorphism, methyltransferase, genotype, allele, association, schizophrenia, disorder, dopaminergic, psychiatric, subjects, polymorphisms, uptake, attention, patients, anxiety, risk, and depression" as the keywords describing commonality among the overlapping candidate genes. As in the PDG-ACE analysis, we made note of the context of these keywords including: psychiatric disorders, neurotransmitter signaling, genetic variation, and attention. GRAIL quantifies similarity among loci (Table 1) and provides a single p-value to characterize the association. Note that ARVCF (Armadillo Repeat gene deletes in Velocardiofacial syndrome, GeneID 421) is adjacent to COMT on chromosome 22, so it is included in the GRAIL gene set.

\section{MiMI network}

The smallest network hypothesized by MiMI that contains all of the overlapping candidate genes has 41 genes

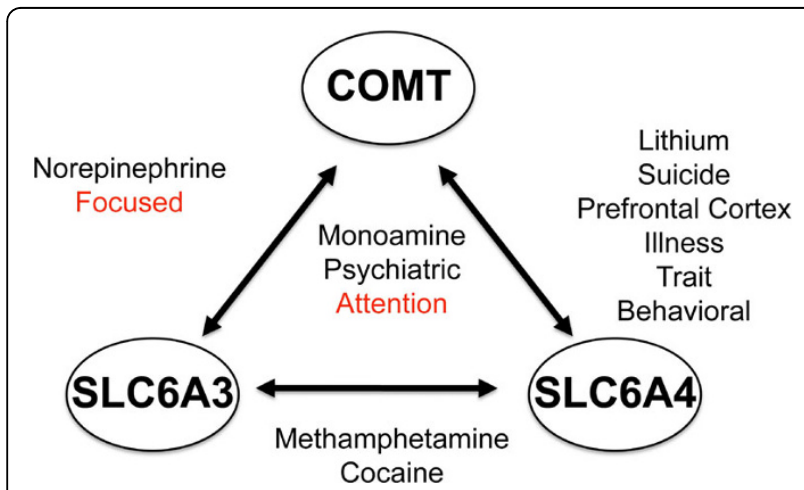

Figure 3 PDG-ACE results. Keywords are significantly overrepresented in the Entrez Gene text at gene pairs (on the edges) or at all three genes (in the middle). These keywords pose hypotheses on the underlying biological associations between candidate genes and all are significantly over-represented (Bonferroni corrected $\mathrm{p}$ value $\leq 0.05$ ). In some cases, these keywords are expected, given the phenotype, while other keywords may reveal novel hypotheses on the underlying etiology associated with the phenotype.
Table 1 GRAIL output

\begin{tabular}{lll}
\hline GENE & $\begin{array}{l}\text { GRAIL } \mathbf{p}- \\
\text { value }\end{array}$ & $\begin{array}{l}\text { SELECTED SIMILAR GENES (Rank in } \\
\text { parantheses) }\end{array}$ \\
\hline COMT & 0.001209104 & ARVCF(5), SLC6A4(12), SLC6A3(25) \\
\hline SLC6A3 & 0.001209104 & SLC6A4(8), COMT(92) \\
\hline SLC6A4 & 0.001209104 & SLC6A3(16), COMT(97) \\
\hline
\end{tabular}

For each overlapping candidate gene, GRAIL quantifies the similarity to the other genes in the set (GRAIL p-value) and ranks genes by similarity. GRAIL also specifies keywords that characterize the similarity (see text).

total (Figure 4). We organized the graphic in three blocks, each anchored by one of the overlapping candidate genes. Table 2 displays the genes in the MiMI network. The MiMI database focuses primarily on proteinprotein binding interactions, so edges in this network represent binding reactions between proteins coded by genes in the network. The genes in this network became input to the GAD analysis.

\section{STRING network}

The smallest network hypothesized by STRING, containing all of the overlapping candidate genes at the highest level of confidence is shown in Figure 5. To connect our overlapping candidates to each other, STRING added four nodes to the network. Genes in the resulting network include the overlapping candidates (COMT, SLC6A3, and SLC6A4) as well as SNCA [(synuclein, alpha (non A4 component of amyloid precursor), GeneID 6622), labeled as NACP in Figure 5]; DRD2 (dopamine receptor D2, GeneID 1813); MAOA (monoamine oxidase A, GeneID 4128); and MAOB (monoamine oxidase B, GeneID 4129). STRING reports multiple types of interactions and Table 3 reports the various association scores among the gene pairs. Note that we have omitted columns of zero scores from Table 3, though STRING also reports neighborhood score, fusion score, co-occurrence score, homology score, and co-expression score. STRING adds nodes based on decreasing "combined score", so DRD2 was the last node added, interacting with COMT, SLC6A3, and SLC6A4. The genes in this network became input to the GAD analysis.

\section{GeneGo networks}

The smallest network hypothesized by GeneGo containing all three of the overlapping candidate genes required adding up to 4 nodes between each of the overlapping candidates, yielding a maximum path length of 5 edges, in a network containing 52 genes (Additional file 4: Figure S1). As with the MiMI and STRING networks, the genes in this network became input to the GAD analysis. This network, modified to include the 17 nodes that connect nicotine to the network (via p53, lower right, and BDNF, top right) is shown in Figure 6. The resulting network contains 69 genes, listed in Table 4, and the graphic is organized to illustrate the feedback loop formed by this network. 


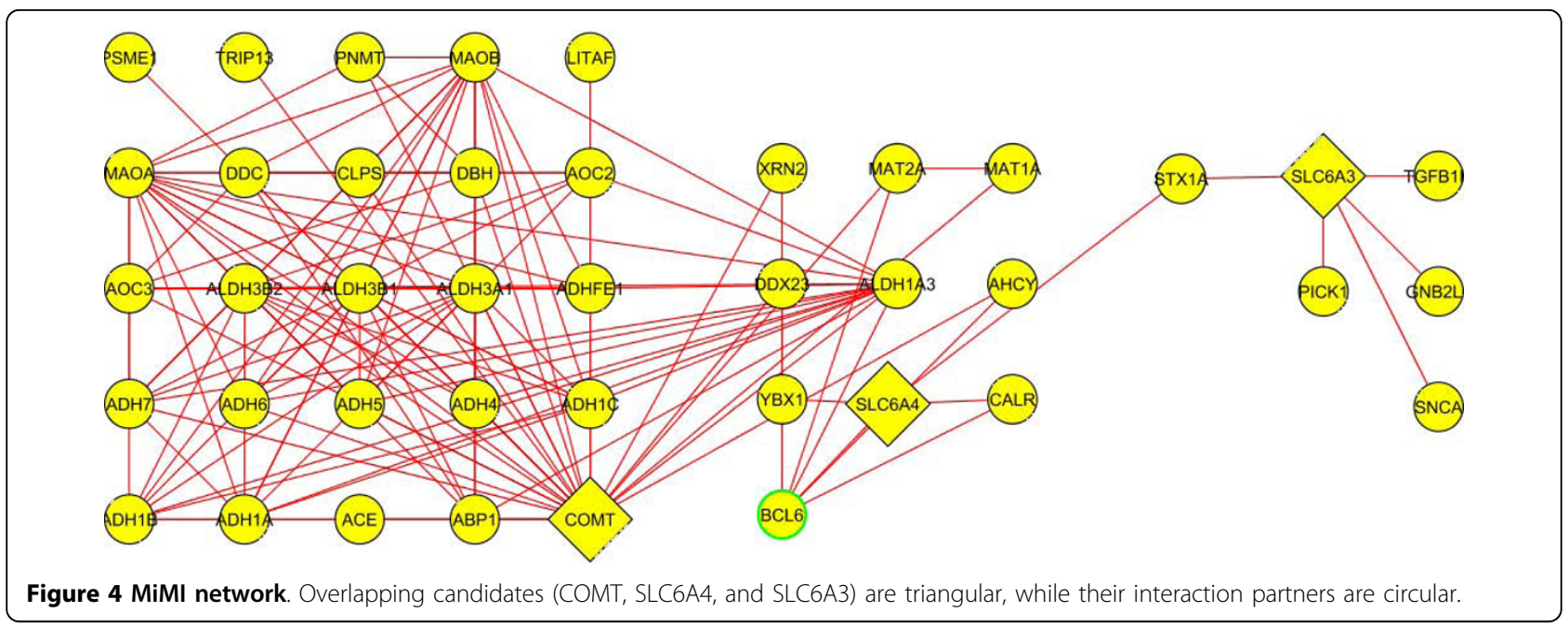

GeneGo's built in pathways analysis did not reveal any significantly over-represented pathways. The 69 genes in this network were used in hypothesis testing via GAD, and subsequently were used in the ConceptGen analysis for differential gene expression.

\section{Hypothesis testing: GAD}

The MiMI network that includes the overlapping candidates (Additional file 3, Table S2) shows significant over-representation of genes associated with both $\mathrm{BD}$ and TUD but the network excluding the overlapping candidates (Additional file 3, Table S3) is not overrepresented for either phenotype.

The STRING network including the overlapping candidates (Additional file 3, Table S4) is significantly associated with multiple measures of both BD and TUD. However, the STRING network that excludes the overlapping candidates (Additional file 3, Table S5) is overrepresented only for "smoking behavior" (FDR 0.87\%) and the more general term "mood disorder" (FDR $0.15 \%)$, rather than $\mathrm{BD}$.
The original GeneGo network, including the overlapping candidates but excluding nicotine, is over-represented for genes associated with both BD and TUD (Additional file 3, Table S6). Excluding the overlapping candidates, this network is over represented only for the general term "depressive disorder, major" (Additional file 3, Table S7). After adding nicotine to this network, the GeneGo network containing 69 genes is over-represented for both BD and TUD associated genes, whether the overlapping candidates are included (Table 5) or excluded (Table 6). Excluding the overlapping candidates, this network is over-represented for genes associated with both "bipolar disorder" (FDR $<0.0001 \%$ ) and "smoking behavior" (FDR $=0.0041 \%$ ).

\section{Hypothesis testing: ConceptGen}

ConceptGen finds that genes in the GeneGo network that includes nicotine are significantly over-represented (FDR 0.029) in one relevant GEO dataset, GSE10718 [79] (Table 7). GSE10718 is titled "Time course of NHBE cells exposed to whole cigarette smoke (full flavor)". Briefly, in

Table 2 Genes included in the MiMI network

\begin{tabular}{|c|c|c|c|c|c|c|c|}
\hline Gene ID & Gene Name & Gene ID & Gene Name & Gene ID & Gene Name & Gene ID & Gene Name \\
\hline 26 & ABP1 & 220 & ALDH1A3 & 1644 & DDC & 6531 & SLC6A3 \\
\hline 1636 & ACE & 218 & ALDH3A1 & 9416 & DDX23 & 6532 & SLC6A4 \\
\hline 124 & $\mathrm{ADH} 1 \mathrm{~A}$ & 221 & ALDH3B1 & 10399 & GNB2L1 & 6622 & SNCA \\
\hline 125 & $\mathrm{ADH} 1 \mathrm{~B}$ & 222 & ALDH3B2 & 9516 & LITAF & 6804 & STX1A \\
\hline 126 & $\mathrm{ADH} 1 \mathrm{C}$ & 314 & $\mathrm{AOC2}$ & 4128 & MAOA & 7041 & TGFB1I1 \\
\hline 127 & $\mathrm{ADH} 4$ & 8639 & $\mathrm{AOC3}$ & 4129 & MAOB & 9319 & TRIP13 \\
\hline 128 & ADH5 & 604 & BCL6 & 4143 & MAT1A & 22803 & XRN2 \\
\hline 130 & ADH6 & 811 & CALR & 4144 & MAT2A & 4904 & YBX1 \\
\hline 131 & ADH7 & 1208 & CLPS & 9463 & PICK1 & & \\
\hline 137872 & ADHFE1 & 1312 & COMT & 5409 & PNMT & & \\
\hline 191 & $\mathrm{AHCY}$ & 1621 & $\mathrm{DBH}$ & 5720 & PSME1 & & \\
\hline
\end{tabular}


Table 3 STRING genes and association scores

\begin{tabular}{llllll}
\hline Node $\mathbf{1}$ & Node $\mathbf{2}$ & Experimental Score & Knowledge Score & Textmining Score & Combined Score \\
\hline NACP & SLC6A3 & 0.873 & 0.9 & 0.481 & 0.993 \\
\hline MAOA & COMT & 0 & 0.9 & 0.91 & 0.991 \\
\hline MAOB & COMT & 0 & 0.9 & 0.848 & 0.984 \\
\hline DRD2 & SLC6A3 & 0.644 & 0 & 0.955 & 0.983 \\
\hline DRD2 & COMT & 0 & 0 & 0.983 & 0.983 \\
\hline DRD2 & SLC6A4 & 0 & 0 & 0.956 & 0.956 \\
\hline SLC6A4 & COMT & 0 & 0 & 0.933 & 0.933
\end{tabular}

Association between each gene pair is characterized by Experimental, Knowledge, and Textmining scores, as well as the Combined score. Columns of zero scores have been omitted.

this experiment, normal human bronchial epithelial cells were exposed to tobacco smoke for 15 minutes, and then incubated for 2 hours in fresh media. Gene expression was assayed on the Affymetrix HG-U133 plus 2 microarray, and differential expression was assessed by the ConceptGen expression analysis pipeline.

\section{SNP prioritization via GIN}

Based on genes in the GeneGo network that includes nicotine, for each SNP assayed in both NicSNP and GAIN, which also shows up in one of our candidate genes, we summed the GIN prioritization score and the transformed p-value $\left[-\log _{10}(\mathrm{p}\right.$-value $\left.)\right]$ from each of the NicSNP and GAIN studies. Additional file 5, Network_cand_SNPs_GIN_NicSNP_GAIN, provides SNPS prioritized for validation.

\section{Discussion}

We found significant epidemiological evidence for increased risk of TUD among BD patients (Figure 2), as well as evidence of increased risk for BD among TUD patients, consistent with a common underlying etiology for these two disorders. There is clear evidence in the

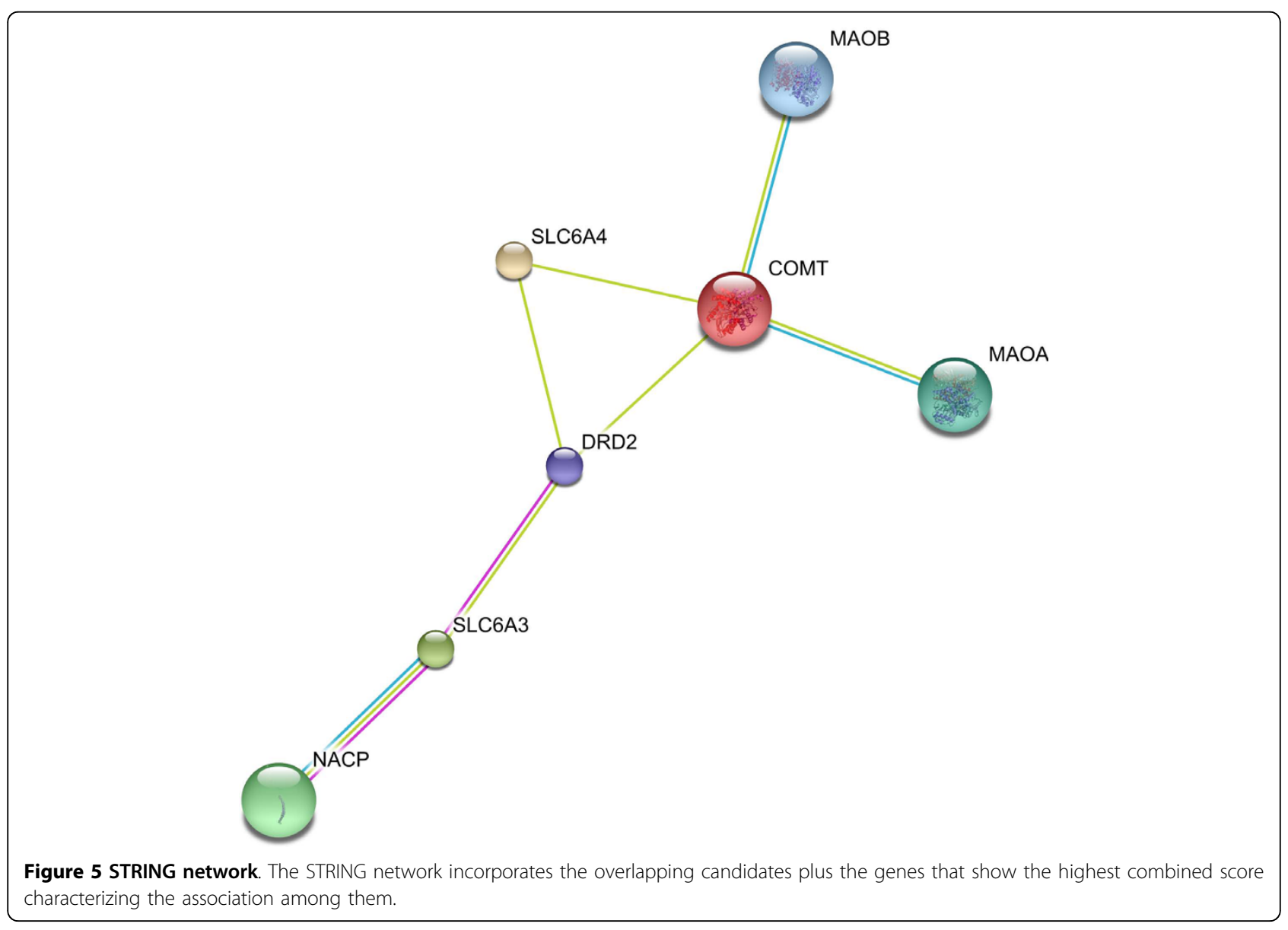




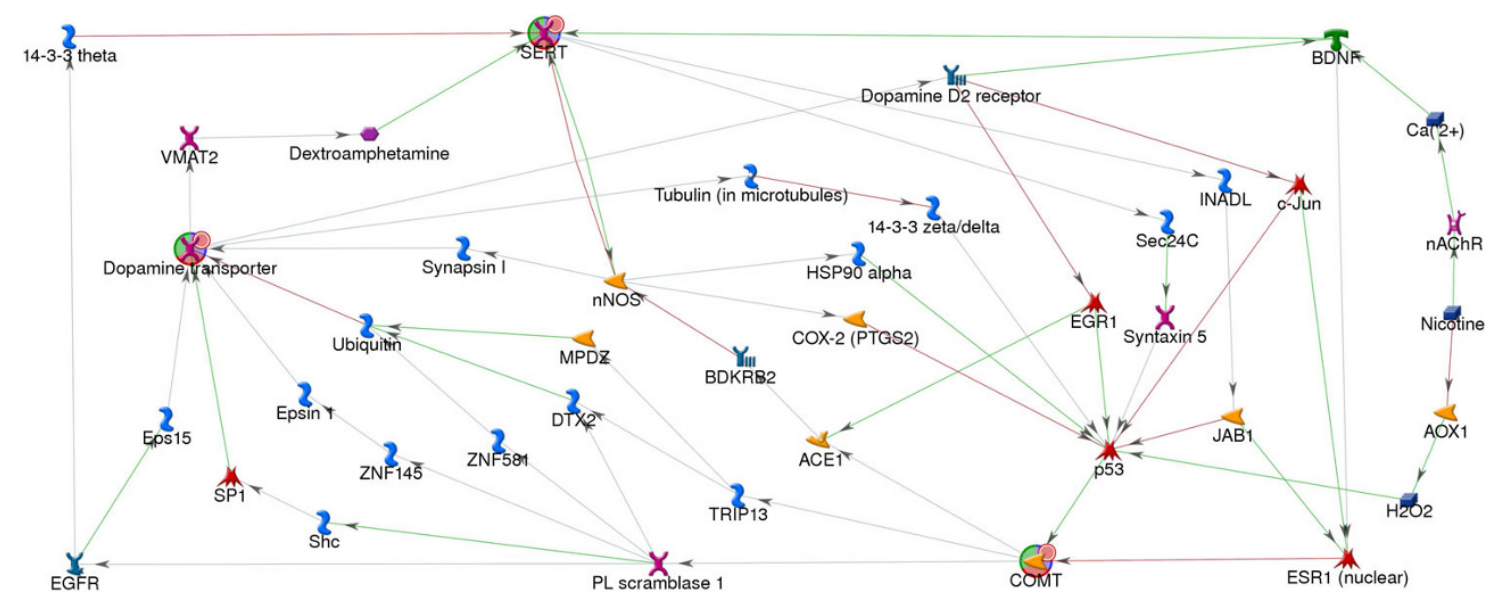

Figure 6 GeneGo network, including nicotine. The GeneGo network connects the overlapping candidates using the smallest number of nodes at the highest level of confidence for the edges. Nicotine and the nodes required to connect nicotine to the network have been added. Overlapping candidate genes (COMT, Dopamine transporter, and SERT) are shown as red, green, and blue circles. Other nodes are coded by the type of protein coded by the gene (e.g. kinases, transporters, etc.). Edges are labeled for direction of effect, where appropriate, and are green for activation or red for repression.

literature that both disorders are influenced by both genetic variation and the environment. Given evidence of common underlying etiology, as well as evidence of genetic and environmental influences on both BD and TUD, we hypothesized a common underlying genetic etiology, interacting with environmental nicotine exposure, influencing susceptibility to comorbid BD and TUD. We used multiple bioinformatics resources to test this hypothesis, including several novel resources.

\section{Meta-analysis}

In the meta-analysis, we estimated relative risk for TUD among BD patients at approximately 2.39 times the risk for the general population. While we cannot discount the possibility of heterogeneity, testing suggests that these seven studies likely are representative of the same population. Equally, all seven studies show an increased Relative Risk for TUD among BD patients and, with the exception of Uock et al., the increased risk is statistically

Table 4 Genes included in the GeneGo network

\begin{tabular}{llllllll}
\hline Gene ID & Gene Name & Gene ID & Gene Name & Gene ID & Gene Name & Gene ID & Gene Name \\
\hline 1636 & ACE & 1145 & CHRNE & 5743 & PTGS2 & 112714 & TUBA3E \\
\hline 316 & AOX1 & 1146 & CHRNG & 6233 & RPS27A & 7277 & TUBA4A \\
\hline 624 & BDKRB2 & 1312 & COMT & 9632 & SEC24C & 51807 & TUBA8 \\
\hline 627 & BDNF & 10987 & COPS5 & 6464 & SHC1 & 203068 & TUBB \\
\hline 1134 & CHRNA1 & 1813 & DRD2 & 6571 & SLC18A2 & 81027 & TUBB1 \\
\hline 57053 & CHRNA10 & 113878 & DTX2 & 6531 & SLC6A3 & 7280 & TUBB2A \\
\hline 1135 & CHRNA2 & 1956 & EGFR & 6532 & SLC6A4 & 347733 & TUBB2B \\
\hline 1136 & CHRNA3 & 1958 & EGR1 & 6667 & SP1 & 10383 & TUBB2C \\
\hline 1137 & CHRNA4 & 29924 & EPN1 & 6811 & STX5 & 10381 & TUBB3 \\
\hline 1138 & CHRNA5 & 2060 & EPS15 & 6853 & SYN1 & 10382 & TUBB4 \\
\hline 8973 & CHRNA6 & 2099 & ESR1 & 7157 & TP53 & 84617 & TUBB6 \\
\hline 1139 & CHRNA7 & 3320 & HSP90AA1 & 9319 & TRIP13 & 7311 & UBA52 \\
\hline 55584 & CHRNA9 & 10207 & INADL & 7846 & TUBA1A & 7314 & UBB \\
\hline 1140 & CHRNB1 & 3725 & JUN & 10376 & TUBA1B & 10971 & YWHAQ \\
\hline 1141 & CHRNB2 & 84708 & LNX1 & 84790 & TUBA1C & 7534 & YWHAZ \\
\hline 1142 & CHRNB3 & 4842 & NOS1 & 7278 & TUBA3C & 7704 & ZBTB16 \\
\hline 1143 & CHRNB4 & 5359 & PLSCR1 & 113457 & TUBA3D & 51545 & ZNF581 \\
\hline 1144 & CHRND & & & &
\end{tabular}


Table 5 GAD testing of the GeneGo network, including nicotine and the overlapping candidates

\begin{tabular}{|c|c|c|c|c|c|c|}
\hline Term & Count & $\%$ & PValue & Genes & $\begin{array}{l}\text { Fold } \\
\text { Enrichment }\end{array}$ & $\begin{array}{l}\text { FDR } \\
\%\end{array}$ \\
\hline cognitive function & 14 & 20.6 & $2.8 \mathrm{E}-18$ & $\begin{array}{l}1137,6531,6532,1138,1312,1813,57053,1135,2099,627,55584, \\
1139,1141,1142,\end{array}$ & 36.0 & 0.000 \\
\hline bipolar disorder & 19 & 27.9 & $7.2 \mathrm{E}-15$ & $\begin{array}{l}1137,6531,1140,1143,8973,6532,1138,1312,1813,1136,57053, \\
1135,1636,627,55584,1134,1139,1141,1142,\end{array}$ & 10.2 & 0.000 \\
\hline smoking behavior & 10 & 14.7 & $1.9 \mathrm{E}-10$ & $6531,627,55584,6532,4842,1139,1312,1141,1813,1142$, & 21.9 & 0.000 \\
\hline Parkinson's disease & 12 & 17.7 & $2.0 \mathrm{E}-07$ & $\begin{array}{l}\text { 1636, 1137, 6853, 2099, 6531, 627, 6532, 5743, 4842, 1312, 1813, } \\
6571,\end{array}$ & 7.3 & 0.000 \\
\hline smoking & 6 & 8.8 & $1.3 \mathrm{E}-05$ & $1636,6531,7157,6532,1141,1813$ & 18.1 & 0.025 \\
\hline methamphetamine abuse & 5 & 7.4 & $2.1 \mathrm{E}-05$ & $6531,627,6532,1312,1813$ & 27.3 & 0.042 \\
\hline alcoholism & 7 & 10.3 & $2.2 \mathrm{E}-05$ & $1636,1137,6531,627,6532,1312,1813$ & 11.3 & 0.042 \\
\hline Alzheimer's disease & 13 & 19.1 & $5.3 \mathrm{E}-05$ & $\begin{array}{l}\text { 1137, 7157, 4842, 6532, 1312, 1136, 9632, 1636, 2099, 627, 5743, } \\
1139,1141,\end{array}$ & 3.8 & 0.104 \\
\hline $\begin{array}{l}\text { attention deficit hyperactivity } \\
\text { disorder }\end{array}$ & 6 & 8.8 & $6.4 \mathrm{E}-05$ & $1137,6531,627,6532,1312,1813$ & 13.1 & 0.125 \\
\hline depression & 6 & 8.8 & $7.2 \mathrm{E}-05$ & $1636,6531,627,6532,1312,1813$ & 12.8 & 0.141 \\
\hline depressive disorder, major & 6 & 8.8 & $1.4 \mathrm{E}-04$ & $2099,627,6532,4842,1139,1813$ & 11.2 & 0.275 \\
\hline tardive dyskinesia & 5 & 7.4 & $1.6 \mathrm{E}-04$ & $6531,6532,4842,1312,1813$ & 16.8 & 0.318 \\
\hline personality traits & 5 & 7.4 & $1.6 \mathrm{E}-04$ & $6531,627,6532,1312,1813$ & 16.8 & 0.318 \\
\hline schizophrenia & 13 & 19.1 & $3.3 \mathrm{E}-04$ & $\begin{array}{l}\text { 1137, 6531, 7157, 4842, 6532, 1312, 1813, 1636, 627, 5743, 1139, } \\
\text { 1141, 6571, }\end{array}$ & 3.1 & 0.645 \\
\hline mood pain & 3 & 4.4 & $3.6 \mathrm{E}-04$ & $627,6532,1312$ & 87.4 & 0.702 \\
\hline suicide & 5 & 7.4 & $3.7 \mathrm{E}-04$ & $1636,6531,6532,4842,1312$ & 13.7 & 0.729 \\
\hline obsessive compulsive disorder & 4 & 5.9 & $5.3 \mathrm{E}-04$ & $6531,627,6532,1312$ & 23.3 & 1.027 \\
\hline Tourette syndrome & 4 & 5.9 & $6.4 \mathrm{E}-04$ & $6531,6532,1312,1813$ & 21.9 & 1.253 \\
\hline eating disorders & 3 & 4.4 & $7.1 \mathrm{E}-04$ & $627,6532,1312$ & 65.6 & 1.390 \\
\hline $\begin{array}{l}\text { alcoholism attention deficit } \\
\text { hyperactivity disorder }\end{array}$ & 3 & 4.4 & $7.1 \mathrm{E}-04$ & $6532,1312,1813$ & 65.6 & 1.390 \\
\hline $\begin{array}{l}\text { alcohol abuse smoking } \\
\text { behavior }\end{array}$ & 3 & 4.4 & $7.1 \mathrm{E}-04$ & $6531,6532,1813$ & 65.6 & 1.390 \\
\hline mood disorder & 4 & 5.9 & 7.7E-04 & $1636,627,6532,1813$ & 20.6 & 1.508 \\
\hline heroin abuse & 4 & 5.9 & 7.7E-04 & $6531,6532,1312,1813$ & 20.6 & 1.508 \\
\hline anorexia nervosa & 4 & 5.9 & $9.2 \mathrm{E}-04$ & $2099,627,6532,1312$ & 19.4 & 1.793 \\
\hline $\begin{array}{l}\text { schizophrenia; tardive } \\
\text { dyskinesia }\end{array}$ & 3 & 4.4 & $1.2 \mathrm{E}-03$ & $627,6532,1312$ & 52.5 & 2.290 \\
\hline $\begin{array}{l}\text { dystonia, acute parkinsonism } \\
\text { tardive dyskinesia }\end{array}$ & 3 & 4.4 & $1.2 \mathrm{E}-03$ & $6531,6532,1813$ & 52.5 & 2.290 \\
\hline neuroticism & 3 & 4.4 & $1.2 \mathrm{E}-03$ & $627,6532,1312$ & 52.5 & 2.290 \\
\hline obsessive-compulsive disorder & 3 & 4.4 & $1.2 \mathrm{E}-03$ & $627,6532,1312$ & 52.5 & 2.290 \\
\hline bipolar disorder schizophrenia & 4 & 5.9 & $1.5 \mathrm{E}-03$ & $627,1139,1312,6571$ & 16.7 & 2.842 \\
\hline $\begin{array}{l}\text { premenstrual dysphoric } \\
\text { disorder }\end{array}$ & 3 & 4.4 & $1.8 \mathrm{E}-03$ & 2099, 6532, 1312, & 43.7 & 3.393 \\
\hline $\begin{array}{l}\text { kidney failure, chronic } \\
\text { polycystic kidney disease }\end{array}$ & 3 & 4.4 & $2.4 \mathrm{E}-03$ & $624,1636,1956$ & 37.5 & 4.687 \\
\hline
\end{tabular}

GAD testing, including nicotine and the overlapping candidates, shows significant over-representation for "bipolar disorder" (BD), "smoking behavior" (TUD), "smoking" (TUD), "alcohol abuse smoking behavior" (TUD) and "bipolar disorder, schizophrenia" (BD). 
Table 6 GAD testing of the GeneGo network, including nicotine but excluding the overlapping candidates

\begin{tabular}{|c|c|c|c|c|c|c|}
\hline Term & Count & $\%$ & PValue & Gene IDs & $\begin{array}{l}\text { Fold } \\
\text { Enrichment }\end{array}$ & FDR \% \\
\hline $\begin{array}{l}\text { bipolar } \\
\text { disorder }\end{array}$ & 16 & 24.6 & $8.5 \mathrm{E}-12$ & $\begin{array}{l}\text { 1137, 1140, 1143, 8973, 1138, 1813, 1136, 57053, 1135, 1636, 627, 55584, 1134, } \\
1139,1141,1142\end{array}$ & 9.34 & 0.0000 \\
\hline $\begin{array}{l}\text { smoking } \\
\text { behavior }\end{array}$ & 7 & 10.8 & $2.1 \mathrm{E}-06$ & $627,55584,4842,1139,1141,1813,1142$ & 16.65 & 0.0041 \\
\hline
\end{tabular}

GAD testing, including nicotine but excluding the overlapping candidates, shows significant over-representation for "bipolar disorder" (BD) and "smoking behavior" (TUD).

significant. We also cannot discount the possibility of publication bias in this analysis. However, the largest and most influential studies, Carney and Grant, were observed in large representative populations and are unlikely to have been influenced by this bias. MIX performed well on our data and we recommend its use for similar meta-analyses. These data are consistent with BD influencing TUD susceptibility, TUD influencing BD susceptibility, or both BD and TUD being influenced by some common element(s).

\section{Gene2MeSH}

To identify candidate genes for the co-morbidity, we searched the extensive literature on both BD and TUD using Gene2MeSH [23]. Gene2MeSH nominates candidate genes that are significantly over-represented in literature annotated for the queried $\mathrm{MeSH}$ term. Gene2MeSH casts a very wide net (all of PubMed) in searching for gene/MeSH term pairs, performs the search in seconds, provides a Fisher Exact p-value to quantify the over-representation of each gene for a given $\mathrm{MeSH}$ term, and sets a threshold of Fisher Exact $\mathrm{p}$-value $\leq 10^{-4}$ to minimize spurious associations. While this p-value threshold is effective minimizing spurious associations, in the case of genes that have strong

Table 7 ConceptGen results

\begin{tabular}{llll}
\hline Gene Symbol & Gene ID & p-value & Fold Chg \\
\hline PTGS2 & 5743 & $5.0 \mathrm{E}-11$ & 3.76 \\
\hline EGR1 & 1958 & $3.7 \mathrm{E}-07$ & 2.45 \\
\hline JUN & 3725 & $5.3 \mathrm{E}-06$ & 1.96 \\
\hline UBB & 7314 & $3.2 \mathrm{E}-09$ & 1.62 \\
\hline HSP90AA1 & 3320 & $4.7 \mathrm{E}-05$ & 1.23 \\
\hline TUBA4A & 7277 & $5.7 \mathrm{E}-06$ & 0.78 \\
\hline EPS15 & 2060 & $3.6 \mathrm{E}-05$ & 0.74 \\
\hline TUBB & 203068 & $7.1 \mathrm{E}-06$ & 0.73 \\
\hline TUBB2C & 10383 & $7.5 \mathrm{E}-07$ & 0.72 \\
\hline ZNF581 & 51545 & $9.1 \mathrm{E}-05$ & 0.71 \\
\hline TUBB6 & 84617 & $4.1 \mathrm{E}-07$ & 0.70 \\
\hline BDKRB2 & 624 & $6.8 \mathrm{E}-05$ & 0.69 \\
\hline TUBB3 & 10381 & $1.1 \mathrm{E}-07$ & 0.59 \\
\hline
\end{tabular}

13 Genes from the selected GeneGo network are differentially expressed with tobacco smoke exposure in GSE10718 (gene symbol and Entrez Gene ID, plus $\mathrm{p}$-value and fold change calculated in the ConceptGen expression analysis pipeline). evidence of association in a relatively small body of literature, this threshold may exclude valid gene/MeSH term pairs. We used three queries for TUD ("tobacco use disorder", "smoking", and "nicotine"), though the query for "smoking" returned all three of the overlapping candidate genes. This suggests that, due to redundancy and ambiguity in MeSH annotation, the user must be wary in choosing the most appropriate $\mathrm{MeSH}$ terms for Gene2MeSH queries.

Gene2MeSH provides links that allow the user to follow the evidence for a gene/MeSH term pair by PubMed query. We used these links to validate our candidate genes by searching the literature for replicated, statistically significant (Bonferroni corrected), positive association with both BD and TUD. This combined threshold for over-representation and replication reduces the chance of a false positive association, though both false positives and false negatives remain possible. For example, both TPH1 and DRD4 show evidence of association with the comorbidity, but do not meet the criteria for replication. Future work may reveal these as true candidate genes for the comorbidity.

Notably, in this analysis and others that rely on published data, there is potential for bias in selecting well studied genes or well studied diseases in developing candidate genes. At the same time, analyses that do not depend on published disease association (e.g. interactions network analysis) may lack relevance to the disease phenotype of interest. We believe that by combining these approaches we minimize the effects of bias and maximize relevance to the phenotype of interest. Gene2$\mathrm{MeSH}$ performed well on our data and provided candidate genes for the analysis and we recommend its use for similar analyses. Alternately, other approaches to candidate gene selection (e.g. GWAS or microarray assay) are useful and could be substituted for Gene2$\mathrm{MeSH}$ in this analysis.

\section{Common elements}

In an effort to understand how our overlapping candidates might interact in predisposing BD and TUD, we tested them for commonality using two relatively new algorithms: PDG-ACE [24,25] and GRAIL[26]. PDGACE finds significant commonality among these genes. Keywords such as "monoamine, psychiatric, 
norepinephrine, prefrontal cortex, illness, trait, and behavioral" are consistent with the expected roles of these genes in a psychiatric disorder. Keywords such as "lithium and suicide" are more specific to BD, while "methamphetamine and cocaine" are consistent with substance use disorders, common comorbidities for BD patients [80]. Keywords "focused and attention" are consistent with both Attention Deficit Disorder [81] and TUD [82]. The first two categories of keywords serve as positive controls, showing that PDG-ACE finds expected relationships among genes that were selected for association with BD and TUD. Note that in earlier testing of PDG-ACE, we used randomly selected locus pairs as negative controls to show that it does not find spurious associations [25]. Reviewing the publications associated with the keywords that PDG-ACE found significant, we found that these genes show gender specific effects in psychiatric and/or substance use disorders. This is consistent with gender differences seen in some studies of TUD susceptibility, though there are also genetic findings for TUD that have consistent effects in both genders $[40,83-85]$. BD susceptibility is often thought to be independent of gender, so the implication is that followon studies of comorbid BD with TUD might benefit from analyses that are stratified by gender or explicitly model gender in association testing. This benefit may extend to independent BD and TUD phenotypes for some genes.

GRAIL produced a set of keywords similar to those produced by PDG-ACE. Keywords "transporter, dopamine, serotonin, uptake, methyltransferase, dopaminergic, and psychiatric", are consistent with the functions of these genes in psychiatric disorders, while "subjects, polymorphisms, patients, risk, genotype, allele, and association" are consistent with the study of the genetic etiology of complex disease. Keywords "depression, anxiety, schizophrenia, disorder, and attention" are consistent with psychiatric disorders but do not highlight the comorbidities of BD with substance use. GRAIL could be improved by providing links to the references used in the analysis, which would allow the user to follow the keywords to assess their potential impact in the disease of interest and, potentially, recognize details such as the gender-specific effects of these genes in psychiatric and substance use disorders.

\section{Network hypothesis generation and testing}

Hypothesis generation via MiMI, STRING, and GeneGo proceeded in parallel. MiMI focuses on protein-protein binding, while STRING and GeneGo also incorporate functional interactions based on the literature. The STRING network includes only 7 genes, the MiMI network includes 41 genes, the smaller GeneGo network includes 52 genes, and the GeneGo network with nicotine contains 69 genes. Testing via the Genetic
Association Database reveals the MiMI, STRING, and smaller GeneGo networks as being generally consistent with the hypothesis. However, when excluding the overlapping candidates none of these networks provides statistically significant evidence in support of the hypothesis.

Only the GeneGo network that includes nicotine is statistically over-represented for genes associated with both BD and TUD. Interpreting these results, we believe that the GeneGo network that includes nicotine illustrates the importance of environmental nicotine exposure in both BD and TUD susceptibility. Consistent with this interpretation, the ConceptGen analysis of this network shows significant over-representation of genes that are differentially expressed with nicotine exposure. Notably, this network forms a feedback loop, where nicotine in the extracellular environment is sensed inside the cell via binding of nicotine to nicotinic acetylcholine receptors, influencing both calcium and neurotransmitter signaling. The environmental influence of nicotine would tend to be amplified over a number of cycles, potentially leading to a growing imbalance in the system with continued exposure. As such, we would expect neurotransmitter and/or calcium signaling to be increasingly imbalanced, over time, with exposure to nicotine. This result is also consistent our original hypothesized interaction between the genetic network and environmental nicotine exposure in predisposing both BD and TUD.

In these analyses, we use GAD for hypothesis testing. While GAD currently has 39,930 records, it remains under development, and it most certainly includes both false positive associations and is missing true associations. Another limitation is that GAD provides only dichotomous disease association data for each gene, which does not account for the strength of the evidence for association, sample size, and methodology. In spite of these limitations, GAD provides a means for obtaining quantitative measures of disease association for genetic networks and will become more valuable as more data are collected and vetted.

We note that the genes identified as being associated with BD and TUD in our GAD analysis are distinct from the genes found to be differentially expressed in the ConceptGen analysis. While this could happen if the data from GAD or ConceptGen represent false positive associations, we believe that this is a result of the differences in hypothesis testing. GAD looks for broad disease association, which could be caused by a range of diseases-related processes. Since we were focused on environmental effects on the network, we tested specifically for differential expression in the ConceptGen analysis. These are not mutually exclusive tests and may represent two views of the same or related phenomena. 
While we emphasize that the selected network model is imperfect, it provides a reasonable model for the complex genetic and environmental influences on BD and TUD comorbidity. Interestingly, it also models other phenotypes. For instance, in the GAD analysis (Table 5) we see "kidney failure, chronic polycystic kidney disease", as a phenotype likely influenced by this network. Kidney failure is clearly a medical phenotype, rather than a psychiatric phenotype, but this network demonstrates genetic influences on the comorbidity and on this medical phenotype $[86,87]$. Consistent with this observation, many genes that are expressed in the brain are expressed in other tissues, so variation that influences psychiatric disorders may have whole body effects and influence what are traditionally considered medical disorders [88-90], thus blurring the boundaries between psychiatric and medical conditions.

\section{Common elements versus network analysis}

In reviewing Table 5, the selected GeneGo network models multiple elements related to BD and TUD including: "cognitive function" [91,92], "Parkinson's disease" $[93,94]$, multiple forms of substance abuse (alcohol, methamphetamine, heroin) [80,95], "attention deficit hyperactivity disorder" [81,82] (ADHD), and "premenstrual dysphoric disorder" [96,97]. Notably, these results are consistent with, and expand upon, the results seen in our PDG-ACE and GRAIL analyses. PDG-ACE keywords "monoamine, psychiatric, norepinephrine, prefrontal cortex, and behavioral", are consistent with network phenotypes "cognitive function" and "Parkinson's disease". PDG-ACE keywords "methamphetamine, and cocaine" are consistent with the network's associations with substance abuse, while PDG-ACE keywords "focused, and attention" are consistent with the network's ADHD association. GRAIL keywords "transporter, dopamine, serotonin, uptake, methyltransferase, and dopaminergic" are consistent with the network phenotypes "cognitive function" and "Parkinson's disease", while GRAIL keyword "attention" is consistent with the network phenotype ADHD. In addition, the gender specific effects we saw in following the PDG-ACE results are consistent with the network phenotype "premenstrual dysphoric disorder".

\section{Validation testing}

Our initial efforts herein have prioritized 14,380 SNPs for validation based on the integration of evidence from GIN and GWAS. No specific biological inquiry has been implemented based on these findings yet, as this work represents a critical first step in planning further experiments. While this is a relatively large number of target SNPs, representing a correspondingly large number of hypothesis tests, the weights provided herein would also allow researchers to select a subset of these SNPs for validation. In addition, based on internal GeneGo annotation, this network proposes multiple potential drug targets for the comorbidity including: EGFR, SLC6A3, SLC6A4, Tubulin, DRD2, COX2, BDKRB2, ACE1, COMT, ESR1, and the NACHRs. Any or all of these genes provide ready targets for drug testing.

\section{Conclusions}

The primary limitation of this approach relates to the validity of the published research in the literature and databases, which may be plagued by type I and II errors. In spite of this limitation, this research highlights several significant points. First, we hypothesized a common underlying genetic etiology, interacting with environmental nicotine exposure, influencing susceptibility for both BD and TUD. We find statistically significant evidence in support of this hypothesis in the selected GeneGo network, both via GAD testing for overrepresentation of $\mathrm{BD}$ and TUD associated genes, and ConceptGen testing for over-representation of differentially expressed genes. We see gender specific effects of our overlapping candidate genes, consistent with stratifying future BD and TUD analyses by gender or explicitly modeling gender in association analysis. Gene2MeSH provides a useful list of candidate genes for a particular phenotype (MeSH term), though it is not an exhaustive list. As seen in the selected GeneGo network, our overlapping Gene2MeSH candidates anchor the network and provide a means of identifying interactions that may be significant in disease, but other genes in the network are also viable candidates. Our definitions of psychiatric and medical conditions may be significantly modified as we progress in identifying genetic influences on complex diseases. Candidate genes and drug targets posed by this network may prove valuable in improving prognosis for patients with this comorbidity. In summary, our systems biology approach provides a model of interacting genetic influences, as well as gene-by-environment interactions, likely to impact comorbid DB with TUD.

\footnotetext{
Additional file 1: Forest Notes. An MS Excel spreadsheet showing the meta analysis input and output data as well as notes describing diagnostic criteria for BD and TUD, test and control population, and derivation of counts for each study.

Click here for file

[http://www.biomedcentral.com/content/supplementary/1471-2350-1114-S1.XLS ]

Additional file 2: MOOSE Checklist. An MS Word document that describes the details of the meta-analysis, consistent with the Reporting Checklist for Authors, Editors, and Reviewers of Meta-analyses of Observational Studies - Meta-analysis of Observational Studies in Epidemiology (MOOSE) criteria.

Click here for file

[http://www.biomedcentral.com/content/supplementary/1471-2350-1114-S2.DOCX]
} 
Additional file 3: Supplementary Tables. An MS word document that provides the MIX meta-analysis summary report (Table S1), and 6 tables of GAD output (Tables S2 through S7).

Click here for file

[http://www.biomedcentral.com/content/supplementary/1471-2350-1114-S3.DOC ]

Additional file 4: Figure S1. A Portable Network Graphics file with the GeneGo network that connects the overlapping candidates using the smallest number of nodes at the highest level of confidence for the edges. Overlapping candidate genes (COMT, Dopamine transporter, and SERT) are shown as red, green, and blue circles. Other nodes are coded by the type of protein coded by the gene (e.g. kinases, transporters, etc.) Edges are labeled for direction of effect, where appropriate, and are green for activation or red for repression.

Click here for file

[http://www.biomedcentral.com/content/supplementary/1471-2350-1114-S4.PNG]

Additional file 5: Network_cand_SNPs_GIN_NicSNP_GAIN. A comma separated text file of candidate SNPs prioritized for validation. Click here for file

[http://www.biomedcentral.com/content/supplementary/1471-2350-1114-S5.CSV]

\section{Abbreviations}

BD: Bipolar Disorder; TUD: Tobacco Use Disorder; PDG-ACE: Prioritizing Disease Genes by Analysis of Common Elements; GRAlL: Gene Relationships Across Implicated Loci; GAD: Genetic Association Database; MiMI: Michigan Molecular Interactions database; STRING: Search Tool for the Retrieval of Interacting Genes/Proteins; COMT: catechol-O-methyltransferase; SLC6A3: solute carrier family 6 (neurotransmitter transporter, dopamine), member 3; SLC6A4: solute carrier family 6 (neurotransmitter transporter, serotonin), member 4; TPH1: tryptophan hydroxylase 1; DRD4: dopamine receptor D4.

\section{Aknowledgements}

This work was supported by National Institutes of Health grant \#U54 DA021519. SFS was supported by K01 DA024722.

\section{Author details}

'Department of Psychiatry, University of Michigan, Ann Arbor, MI, USA. ${ }^{2}$ National Center for Integrative Biomedical Informatics, University of Michigan, Ann Arbor, MI, USA. ${ }^{3}$ Department of Genetics, Washington University, Saint Louis, MO, USA. ${ }^{4}$ Department of Psychiatry, Washington University, Saint Louis, MO, USA. ${ }^{5}$ Department of Biology, Eastern Michigan University, Ypsilanti, MI, USA.

\section{Authors' contributions}

RCM conceived and initiated the study and was responsible for overall completion of the study. NLS and SFS provided expertise on nicotine and the NicSNP data. YDK, TK, and RKK provided research on drug effects, gender specific effects, and medical effects on the comorbidity, respectively. ASA and MAS provided expertise on Gene2MeSH and ConceptGen, respectively. JDC and MGM provided expert advice on study design and execution, and Bipolar Disorder. All authors read and approved the final manuscript.

\section{Competing interests}

Financial: MGM has served as a consultant or on the speaker's bureau for Lilly, Pfizer, Merck, Astra-Zeneca, and Janssen Pharmaceuticals. SFS is listed as an inventor on a patent (US 20070258898) covering the use of certain SNPs in determining the diagnosis, prognosis, and treatment of addiction. NLS is the spouse of SFS and thus connected to the above patent. Non-financial: none.

Received: 10 July 2009

Accepted: 26 January 2010 Published: 26 January 2010

\section{References}

1. Grant BF, Stinson FS, Hasin DS, Dawson DA, Chou SP, Ruan WJ, Huang B: Prevalence, correlates, and comorbidity of bipolar I disorder and axis I and II disorders: results from the National Epidemiologic Survey on Alcohol and Related Conditions. J Clin Psychiatry 2005, 66:1205-1215.

2. Merikangas KR, Akiskal HS, Angst J, Greenberg PE, Hirschfeld RM, Petukhova M, Kessler RC: Lifetime and 12-month prevalence of bipolar spectrum disorder in the National Comorbidity Survey replication. Arch Gen Psychiatry 2007, 64:543-552.

3. Finney Rutten LJ, Augustson EM, Moser RP, Beckjord EB, Hesse BW: Smoking knowledge and behavior in the United States: sociodemographic, smoking status, and geographic patterns. Nicotine Tob Res 2008, 10:1559-1570.

4. Carmelli D, Swan GE, Robinette D, Fabsitz R: Genetic influence on smoking-a study of male twins. N Engl J Med 1992, 327:829-833.

5. Vanable PA, Carey MP, Carey KB, Maisto SA: Smoking among psychiatric outpatients: relationship to substance use, diagnosis, and illness severity. Psychol Addict Behav 2003, 17:259-265.

6. MeSH. http://www.ncbi.n/m.nih.gov/sites/entrez?db=mesh.

7. Carney CP, Jones LE: Medical comorbidity in women and men with bipolar disorders: a population-based controlled study. Psychosom Med 2006, 68:684-691.

8. Hughes JR, Hatsukami DK, Mitchell JE, Dahlgren LA: Prevalence of smoking among psychiatric outpatients. Am J Psychiatry 1986, 143:993-997.

9. Gonzalez-Pinto A, Gutierrez M, Ezcurra J, Aizpuru F, Mosquera F, Lopez P, de Leon J: Tobacco smoking and bipolar disorder. J Clin Psychiatry 1998, 59:225-228.

10. Lasser K, Boyd JW, Woolhandler S, Himmelstein DU, McCormick D, Bor DH: Smoking and mental illness: A population-based prevalence study. Jama 2000, 284:2606-2610.

11. Ucok A, Polat A, Bozkurt O, Meteris H: Cigarette smoking among patients with schizophrenia and bipolar disorders. Psychiatry Clin Neurosci 2004, 58:434-437.

12. Wilens TE, Biederman J, Adamson JJ, Henin A, Sgambati S, Gignac M, Sawtelle R, Santry A, Monuteaux MC: Further evidence of an association between adolescent bipolar disorder with smoking and substance use disorders: a controlled study. Drug Alcohol Depend 2008, 95:188-198.

13. Burmeister M, Mclnnis MG, Zollner S: Psychiatric genetics: progress amid controversy. Nat Rev Genet 2008, 9:527-540.

14. Lerman CE, Schnoll RA, Munafo MR: Genetics and smoking cessation improving outcomes in smokers at risk. Am J Prev Med 2007, 33:5398-405.

15. McGuffin P, Rijsdijk F, Andrew M, Sham P, Katz R, Cardno A: The heritability of bipolar affective disorder and the genetic relationship to unipolar depression. Arch Gen Psychiatry 2003, 60:497-502.

16. Edvardsen J, Torgersen S, Roysamb E, Lygren S, Skre I, Onstad S, Oien PA: Heritability of bipolar spectrum disorders. Unity or heterogeneity?. J Affect Disord 2008, 106:229-240.

17. Bertelsen A, Harvald B, Hauge M: A Danish twin study of manicdepressive disorders. Br J Psychiatry 1977, 130:330-351.

18. Li MD, Cheng R, Ma JZ, Swan GE: A meta-analysis of estimated genetic and environmental effects on smoking behavior in male and female adult twins. Addiction 2003, 98:23-31.

19. Lerman $C$, Berrettini W: Elucidating the role of genetic factors in smoking behavior and nicotine dependence. Am J Med Genet B Neuropsychiatr Genet 2003, 118B:48-54.

20. Bax L, Yu LM, Ikeda N, Tsuruta H, Moons KG: Development and validation of MIX: comprehensive free software for meta-analysis of causal research data. BMC Med Res Methodol 2006, 6:50.

21. Bax L YL, Ikeda N, Tsuruta H, Moons KGM: MIX: comprehensive free software for meta-analysis of causal research data. Book MIX: comprehensive free software for meta-analysis of causal research data. (Editor ed.^eds.), Version 1.7 edition. City 2008.

22. Stroup DF, Berlin JA, Morton SC, Olkin I, Williamson GD, Rennie D, Moher D, Becker BJ, Sipe TA, Thacker SB: Meta-analysis of observational studies in epidemiology: a proposal for reporting. Meta-analysis Of Observational Studies in Epidemiology (MOOSE) group. Jama 2000, 283:2008-2012.

23. Gene2MeSH. http://gene2mesh.ncibi.org.

24. McEachin RC, Keller BJ, Zandi PP, Almani M, Mclnnis MG: Prioritizing Disease Genes by Analysis of Common Elements (PDG-ACE). AMIA Annu Symp Proc 2007, 1068. 
25. Keller BJ, McEachin RC: Identifying hypothetical genetic influences on complex disease phenotypes. BMC Bioinformatics 2009, 10(Suppl 2):S13.

26. Raychaudhuri S, Plenge RM, Rossin EJ, Ng AC, Purcell SM, Sklar P, Scolnick EM, Xavier RJ, Altshuler D, Daly MJ: Identifying relationships among genomic disease regions: predicting genes at pathogenic SNP associations and rare deletions. PLoS Genet 2009, 5:e1000534.

27. Tarcea VG, Weymouth T, Ade A, Bookvich A, Gao J, Mahavisno V, Wright Z, Chapman A, Jayapandian M, Ozgur A, et al: Michigan molecular interactions r2: from interacting proteins to pathways. Nucleic Acids Res 2009, 37:D642-646.

28. von Mering C, Huynen M, Jaeggi D, Schmidt S, Bork P, Snel B: STRING: a database of predicted functional associations between proteins. Nucleic Acids Res 2003, 31:258-261.

29. von Mering C, Jensen $L$, Kuhn M, Chaffron S, Doerks T, Kruger B, Snel B, Bork P: STRING 7-recent developments in the integration and prediction of protein interactions. Nucleic Acids Res 2007, 35:D358-362.

30. Ekins S, Nikolsky Y, Bugrim A, Kirillov E, Nikolskaya T: Pathway mapping tools for analysis of high content data. Methods Mol Biol 2007, 356:319-350

31. Gao J, Ade AS, Tarcea VG, Weymouth TE, Mirel BR, Jagadish HV, States DJ: Integrating and annotating the interactome using the MiMl plugin for cytoscape. Bioinformatics 2009, 25:137-138.

32. Becker KG, Barnes KC, Bright TJ, Wang SA: The genetic association database. Nat Genet 2004, 36:431-432

33. Dennis G, Sherman BT Jr, Hosack DA, Yang J, Gao W, Lane HC, Lempicki RA DAVID: Database for Annotation, Visualization, and Integrated Discovery. Genome Biol 2003, 4:P3.

34. Huang da W, Sherman BT, Lempicki RA: Systematic and integrative analysis of large gene lists using DAVID bioinformatics resources. Nat Protoc 2009, 4:44-57.

35. Sartor MA, Mahavisno V, Keshamouni VG, Cavalcoli J, Wright Z, Karnovsky A, Kuick R, Jagadish HV, Mirel B, Weymouth T, et al: ConceptGen: a gene set enrichment and gene set relation mapping tool. Bioinformatics 2009

36. Edgar R, Domrachev M, Lash AE: Gene Expression Omnibus: NCBI gene expression and hybridization array data repository. Nucleic Acids Res 2002, 30:207-210.

37. Sartor MA, Tomlinson CR, Wesselkamper SC, Sivaganesan S, Leikauf GD, Medvedovic M: Intensity-based hierarchical Bayes method improves testing for differentially expressed genes in microarray experiments. BMC Bioinformatics 2006, 7:538

38. Saccone SF, Saccone NL, Swan GE, Madden PA, Goate AM, Rice JP, Bierut $L$ : Systematic biological prioritization after a genome-wide association study: an application to nicotine dependence. Bioinformatics 2008, 24:1805-1811.

39. Bierut LJ, Madden PA, Breslau N, Johnson EO, Hatsukami D, Pomerleau OF, Swan GE, Rutter J, Bertelsen S, Fox L, et al: Novel genes identified in a high-density genome wide association study for nicotine dependence. Hum Mol Genet 2007, 16:24-35.

40. Saccone SF, Hinrichs AL, Saccone NL, Chase GA, Konvicka K, Madden PA, Breslau N, Johnson EO, Hatsukami D, Pomerleau O, et al: Cholinergic nicotinic receptor genes implicated in a nicotine dependence association study targeting 348 candidate genes with 3713 SNPs. Hum Mol Genet 2007, 16:36-49.

41. Smith EN, Bloss CS, Badner JA, Barrett T, Belmonte PL, Berrettini W, Byerley W, Coryell W, Craig D, Edenberg HJ, et al: Genome-wide association study of bipolar disorder in European American and African American individuals. Mol Psychiatry 2009, 14:755-763.

42. Beuten J, Payne TJ, Ma JZ, Li MD: Significant association of catechol-Omethyltransferase (COMT) haplotypes with nicotine dependence in male and female smokers of two ethnic populations. Neuropsychopharmacology 2006, 31:675-684.

43. Colilla S, Lerman C, Shields PG, Jepson C, Rukstalis M, Berlin J, DeMichele A, Bunin G, Strom BL, Rebbeck TR: Association of catechol-Omethyltransferase with smoking cessation in two independent studies of women. Pharmacogenet Genomics 2005, 15:393-398.

44. Enoch MA, Waheed JF, Harris CR, Albaugh B, Goldman D: Sex differences in the influence of COMT Val158Met on alcoholism and smoking in plains American Indians. Alcohol Clin Exp Res 2006, 30:399-406.

45. Munafo MR, Johnstone EC, Guo B, Murphy MF, Aveyard P: Association of COMT Val108/158Met genotype with smoking cessation. Pharmacogenet Genomics 2008, 18:121-128
46. Burdick KE, Funke B, Goldberg JF, Bates JA, Jaeger J, Kucherlapati R, Malhotra AK: COMT genotype increases risk for bipolar I disorder and influences neurocognitive performance. Bipolar Disord 2007, 9:370-376.

47. Shifman S, Bronstein M, Sternfeld M, Pisante A, Weizman A, Reznik I, Spivak B, Grisaru N, Karp L, Schiffer R, et al: COMT: a common susceptibility gene in bipolar disorder and schizophrenia. Am J Med Genet B Neuropsychiatr Genet 2004, 128B:61-64.

48. Erblich J, Lerman C, Self DW, Diaz GA, Bovbjerg DH: Effects of dopamine D2 receptor (DRD2) and transporter (SLC6A3) polymorphisms on smoking cue-induced cigarette craving among African-American smokers. Mol Psychiatry 2005, 10:407-414.

49. Ling $D$, Niu $T$, Feng $Y$, Xing $H, X u X$ : Association between polymorphism of the dopamine transporter gene and early smoking onset: an interaction risk on nicotine dependence. J Hum Genet 2004, 49:35-39.

50. O'Gara C, Stapleton J, Sutherland G, Guindalini C, Neale B, Breen G, Ball D: Dopamine transporter polymorphisms are associated with short-term response to smoking cessation treatment. Pharmacogenet Genomics 2007, 17:61-67.

51. Segman RH, Kanyas K, Karni O, Lerer E, Goltser-Dubner T, Pavlov V, Lerer B: Why do young women smoke? IV. Role of genetic variation in the dopamine transporter and lifetime traumatic experience. Am J Med Genet B Neuropsychiatr Genet 2007, 144B:533-540.

52. Stapleton JA, Sutherland G, O'Gara C: Association between dopamine transporter genotypes and smoking cessation: a meta-analysis. Addict Biol 2007, 12:221-226.

53. Greenwood TA, Alexander M, Keck PE, McElroy S, Sadovnick AD, Remick RA, Kelsoe JR: Evidence for linkage disequilibrium between the dopamine transporter and bipolar disorder. Am J Med Genet 2001, 105:145-151.

54. Greenwood TA, Schork NJ, Eskin E, Kelsoe JR: Identification of additional variants within the human dopamine transporter gene provides further evidence for an association with bipolar disorder in two independent samples. Mol Psychiatry 2006, 11:125-133, 115.

55. Keikhaee MR, Fadai F, Sargolzaee MR, Javanbakht A, Najmabadi H, Ohadi M: Association analysis of the dopamine transporter (DAT1)-67A/T polymorphism in bipolar disorder. Am J Med Genet B Neuropsychiatr Genet 2005, 135B:47-49.

56. Mick E, Kim JW, Biederman J, Wozniak J, Wilens T, Spencer T, Smoller JW, Faraone SV: Family based association study of pediatric bipolar disorder and the dopamine transporter gene (SLC6A3). Am J Med Genet B Neuropsychiatr Genet 2008, 147B:1182-1185.

57. Ohadi M, Keikhaee MR, Javanbakht A, Sargolzaee MR, Robabeh M, Najmabadi H: Gender dimorphism in the DAT1-67 T-allele homozygosity and predisposition to bipolar disorder. Brain Res 2007, 1144:142-145.

58. Gerra G, Garofano L, Zaimovic A, Moi G, Branchi B, Bussandri M, Brambilla F, Donnini C: Association of the serotonin transporter promoter polymorphism with smoking behavior among adolescents. Am J Med Genet B Neuropsychiatr Genet 2005, 135B:73-78.

59. Kremer I, Bachner-Melman R, Reshef A, Broude L, Nemanov L, Gritsenko I, Heresco-Levy U, Elizur Y, Ebstein RP: Association of the serotonin transporter gene with smoking behavior. Am J Psychiatry 2005, 162:924-930

60. Anguelova M, Benkelfat C, Turecki G: A systematic review of association studies investigating genes coding for serotonin receptors and the serotonin transporter: I. Affective disorders. Mol Psychiatry 2003, 8:574-591.

61. Cho HJ, Meira-Lima I, Cordeiro Q, Michelon L, Sham P, Vallada H, Collier DA Population-based and family-based studies on the serotonin transporter gene polymorphisms and bipolar disorder: a systematic review and meta-analysis. Mol Psychiatry 2005, 10:771-781.

62. Lasky-Su JA, Faraone SV, Glatt SJ, Tsuang MT: Meta-analysis of the association between two polymorphisms in the serotonin transporter gene and affective disorders. Am J Med Genet B Neuropsychiatr Genet 2005, 133B:110-115.

63. Mynett-Johnson L, Kealey C, Claffey E, Curtis D, Bouchier-Hayes L, Powell C, McKeon P: Multimarkerhaplotypes within the serotonin transporter gene suggest evidence of an association with bipolar disorder. Am J Med Genet 2000, 96:845-849.

64. Alsobrook JP, Zohar AH, Leboyer M, Chabane N, Ebstein RP, Pauls DL: Association between the COMT locus and obsessive-compulsive disorder in females but not males. Am J Med Genet 2002, 114:116-120. 
65. Baca-Garcia E, Vaquero C, Diaz-Sastre C, Saiz-Ruiz J, Fernandez-Piqueras J, de Leon J: A gender-specific association between the serotonin transporter gene and suicide attempts. Neuropsychopharmacology 2002, 26:692-695.

66. Baud P, Courtet P, Perroud N, Jollant F, Buresi C, Malafosse A: Catechol-Omethyltransferase polymorphism (COMT) in suicide attempters: a possible gender effect on anger traits. Am J Med Genet B Neuropsychiatr Genet 2007, 144B:1042-1047.

67. Beaver KM, Wright JP, DeLisi M: Delinquent peer group formation: evidence of a gene $\times$ environment correlation. J Genet Psychol 2008, 169:227-244.

68. Denys D, Van Nieuwerburgh F, Deforce D, Westenberg H: Association between the dopamine D2 receptor Taql A2 allele and low activity COMT allele with obsessive-compulsive disorder in males. Eur Neuropsychopharmacol 2006, 16:446-450.

69. Domschke K, Deckert J, O'Donovan MC, Glatt SJ: Meta-analysis of COMT val158met in panic disorder: ethnic heterogeneity and gender specificity. Am J Med Genet B Neuropsychiatr Genet 2007, 144B:667-673.

70. Eley TC, Tahir E, Angleitner A, Harriss K, McClay J, Plomin R, Riemann R, Spinath F, Craig I: Association analysis of MAOA and COMT with neuroticism assessed by peers. Am J Med Genet B Neuropsychiatr Genet 2003, 120B:90-96.

71. Galeeva AR, Gareeva AE, lur'ev EB, Khusnutdinova EK: [VNTR polymorphisms of the serotonin transporter and dopamine transporter genes in male opiate addicts]. Mol Biol (Mosk) 2002, 36:593-598.

72. Kim SJ, Kim YS, Kim SY, Lee HS, Kim CH: An association study of catecholO-methyltransferase and monoamine oxidase A polymorphisms and personality traits in Koreans. Neurosci Lett 2006, 401:154-158.

73. Lee HK: Association of the serotonin transporter gene polymorphism with Korean male alcoholics. Nihon Arukoru Yakubutsu lgakkai Zasshi 2007, 42:602-604.

74. Lin JJ, Yueh KC, Chang DC, Chang CY, Yeh YH, Lin SZ: The homozygote 10-copy genotype of variable number tandem repeat dopamine transporter gene may confer protection against Parkinson's disease for male, but not to female patients. J Neurol Sci 2003, 209:87-92.

75. Mandelli L, Serretti A, Marino E, Pirovano A, Calati R, Colombo C: Interaction between serotonin transporter gene, catechol-Omethyltransferase gene and stressful life events in mood disorders. Int J Neuropsychopharmacol 2007, 10:437-447.

76. Olsson CA, Anney RJ, Lotfi-Miri M, Byrnes GB, Williamson R, Patton GC: Association between the COMT Val158Met polymorphism and propensity to anxiety in an Australian population-based longitudinal study of adolescent health. Psychiatr Genet 2005, 15:109-115.

77. Ono H, Shirakawa O, Nushida H, Ueno Y, Maeda K: Association between catechol-O-methyltransferase functional polymorphism and male suicide completers. Neuropsychopharmacology 2004, 29:1374-1377.

78. Sookoian S, Gianotti TF, Gemma C, Burgueno A, Pirola CJ: Contribution of the functional 5-HTTLPR variant of the SLC6A4 gene to obesity risk in male adults. Obesity (Silver Spring) 2008, 16:488-491.

79. Jorgensen E, Stinson A, Shan L, Yang J, Gietl D, Albino AP: Cigarette smoke induces endoplasmic reticulum stress and the unfolded protein response in normal and malignant human lung cells. BMC Cancer 2008, 8:229.

80. Strakowski SM, DelBello MP: The co-occurrence of bipolar and substance use disorders. Clin Psychol Rev 2000, 20:191-206.

81. Singh MK, DelBello MP, Kowatch RA, Strakowski SM: Co-occurrence of bipolar and attention-deficit hyperactivity disorders in children. Bipolar Disord 2006, 8:710-720

82. McClernon FJ, Kollins SH: ADHD and smoking: from genes to brain to behavior. Ann N Y Acad Sci 2008, 1141:131-147.

83. Berrettini W, Yuan X, Tozzi F, Song K, Francks C, Chilcoat H, Waterworth D, Muglia P, Mooser V: Alpha-5/alpha-3 nicotinic receptor subunit alleles increase risk for heavy smoking. Mol Psychiatry 2008, 13:368-373.

84. Thorgeirsson TE, Stefansson K: Genetics of smoking behavior and its consequences: the role of nicotinic acetylcholine receptors. Biol Psychiatry 2008, 64:919-921.

85. Thorgeirsson TE, Geller F, Sulem P, Rafnar T, Wiste A, Magnusson KP, Manolescu A, Thorleifsson G, Stefansson $H$, Ingason A, et al: A variant associated with nicotine dependence, lung cancer and peripheral arterial disease. Nature 2008, 452:638-642.

86. Cooper RG: Effect of tobacco smoking on renal function. Indian J Med Res 2006, 124:261-268
87. Raedler TJ, Wiedemann K: Lithium-induced nephropathies. Psychopharmacol Bull 2007, 40:134-149.

88. Waterreus AJ, Laugharne JD: Screening for the metabolic syndrome in patients receiving antipsychotic treatment: a proposed algorithm. Med J Aust 2009, 190:185-189.

89. Grippo AJ, Johnson AK: Stress, depression and cardiovascular dysregulation: a review of neurobiological mechanisms and the integration of research from preclinical disease models. Stress 2009, 12:1-21.

90. O'Keane V: Antipsychotic-induced hyperprolactinaemia, hypogonadism and osteoporosis in the treatment of schizophrenia. J Psychopharmacol 2008, 22:70-75.

91. Clark L, Sahakian BJ: Cognitive neuroscience and brain imaging in bipolar disorder. Dialogues Clin Neurosci 2008, 10:153-163.

92. Kenney JW, Gould TJ: Modulation of hippocampus-dependent learning and synaptic plasticity by nicotine. Mol Neurobiol 2008, 38:101-121.

93. Berk M, Dodd S, Kauer-Sant'anna M, Malhi GS, Bourin M, Kapczinski F, Norman T: Dopamine dysregulation syndrome: implications for a dopamine hypothesis of bipolar disorder. Acta Psychiatr Scand Supp/ 2007, 41-49.

94. Quik M, O'Leary K, Tanner CM: Nicotine and Parkinson's disease: implications for therapy. Mov Disord 2008, 23:1641-1652.

95. McIntyre RS, Nguyen HT, Soczynska JK, Lourenco MT, Woldeyohannes HO, Konarski JZ: Medical and substance-related comorbidity in bipolar disorder: translational research and treatment opportunities. Dialogues Clin Neurosci 2008, 10:203-213.

96. Goodnick PJ, Chaudry T, Artadi J, Arcey S: Women's issues in mood disorders. Expert Opin Pharmacother 2000, 1:903-916.

97. Franklin TR, Ehrman R, Lynch KG, Harper D, Sciortino N, O'Brien CP, Childress AR: Menstrual cycle phase at quit date predicts smoking status in an NRT treatment trial: a retrospective analysis. J Womens Health (Larchmt) 2008, 17:287-292.

\section{Pre-publication history}

The pre-publication history for this paper can be accessed here:http://www biomedcentral.com/1471-2350/11/14/prepub

doi:10.1186/1471-2350-11-14

Cite this article as: McEachin et al:: Modeling complex genetic and environmental influences on comorbid bipolar disorder with tobacco use disorder. BMC Medical Genetics 2010 11:14.

\section{Publish with Bio Med Central and every scientist can read your work free of charge}

"BioMed Central will be the most significant development for disseminating the results of biomedical research in our lifetime. "

Sir Paul Nurse, Cancer Research UK

Your research papers will be:

- available free of charge to the entire biomedical community

- peer reviewed and published immediately upon acceptance

- cited in PubMed and archived on PubMed Central

- yours - you keep the copyright 